\title{
Lower iodine storage in the placenta is associated with gestational diabetes mellitus
}

Kristof Y. Neven ${ }^{1}$, Bianca Cox ${ }^{1}$, Charlotte Cosemans ${ }^{1}$, Wilfried Gyselaers², Joris Penders ${ }^{3}$, Michelle Plusquin ${ }^{1}$, Harry A. Roels ${ }^{1,4}$, Karen Vrijens ${ }^{1}$, Ann Ruttens ${ }^{5}$ and Tim S. Nawrot ${ }^{1,6^{*}}$ (D)

\begin{abstract}
Background: The micronutrient iodine is essential for a healthy intrauterine environment and is required for optimal fetal growth and neurodevelopment. Evidence linking urinary iodine concentrations, which mainly reflects short-term iodine intake, to gestational diabetes mellitus (GDM) is inconclusive. Although the placental concentrations would better reflect the long-term gestational iodine status, no studies to date have investigated the association between the placental iodine load and the risk at GDM. Moreover, evidence is lacking whether placental iodine could play a role in biomarkers of insulin resistance and $\beta$-cell activity.
\end{abstract}

Methods: We assessed the incidence of GDM between weeks 24 and 28 of gestation for 471 mother-neonate pairs from the ENVIRONAGE birth cohort. In placentas, we determined the iodine concentrations. In maternal and cord blood, we measured the insulin concentrations, the Homeostasis Model Assessment (HOMA) for insulin resistance (IR) index, and $\beta$-cell activity. Logistic regression was used to estimate the odds ratios (OR) of GDM, and the population attributable factor (PAF) was calculated. Generalized linear models estimated the changes in insulin, HOMA-IR, and $\beta$-cell activity for a $5 \mu \mathrm{g} / \mathrm{kg}$ increase in placental iodine.

Results: Higher placental iodine concentrations decreased the risk at GDM (OR=0.82; $95 \% \mathrm{Cl} 0.72$ to $0.93 ; p=0.003)$. According to the PAF, $54.2 \%(95 \% \mathrm{Cl} 11.4$ to $82.3 \%$; $p=0.0006)$ of the GDM cases could be prevented if the mothers of the lowest tertile of placental iodine would have placental iodine levels as those belonging to the highest tertile. In cord blood, the plasma insulin concentration was inversely associated with the placental iodine load $(\beta=-4.8 \%$; $95 \% \mathrm{Cl}-8.9$ to $-0.6 \% ; p=0.026)$.

Conclusions: Higher concentrations of placental iodine are linked with a lower incidence of GDM. Moreover, a lower placental iodine load is associated with an altered plasma insulin concentration, HOMA-IR index, and $\beta$-cell activity. These findings postulate that a mild-to-moderate iodine deficiency could be linked with subclinical and early-onset alterations in the normal insulin homeostasis in healthy pregnant women. Nevertheless, the functional link between gestational iodine status and GDM warrants further research.

Keywords: Neonates, Placenta, lodine, ICP-MS, Gestational diabetes mellitus, Pregnancy, DOHaD

\footnotetext{
* Correspondence: tim.nawrot@uhasselt.be

${ }^{1}$ Centre for Environmental Sciences, Hasselt University, Diepenbeek, Belgium

${ }^{6}$ Department of Public Health \& Primary Care, Leuven University, Leuven, Belgium

Full list of author information is available at the end of the article
}

C The Author(s). 2021 Open Access This article is licensed under a Creative Commons Attribution 4.0 International License, which permits use, sharing, adaptation, distribution and reproduction in any medium or format, as long as you give appropriate credit to the original author(s) and the source, provide a link to the Creative Commons licence, and indicate if changes were made. The images or other third party material in this article are included in the article's Creative Commons licence, unless indicated otherwise in a credit line to the material. If material is not included in the article's Creative Commons licence and your intended use is not permitted by statutory regulation or exceeds the permitted use, you will need to obtain permission directly from the copyright holder. To view a copy of this licence, visit http://creativecommons.org/licenses/by/4.0/. The Creative Commons Public Domain Dedication waiver (http://creativecommons.org/publicdomain/zero/1.0/) applies to the data made available in this article, unless otherwise stated in a credit line to the data. 


\section{Background}

Gestational diabetes mellitus (GDM) is a disease that is characterized by glucose intolerance with onset during the pregnancy and which attenuates after delivery [1]. Generally, $5 \%$ of all pregnancies are complicated by GDM [2], adversely affecting the intrauterine environment, which may in turn lead to congenital abnormalities and even spontaneous abortions [3]. Postpartum complications include a 7.5-fold increased risk at type 2 diabetes mellitus (T2DM) for the mothers [4] and a higher risk at obesity [5] and diabetes mellitus [5] for the offspring. There are well-established GDM risk factors such as a high body mass index (BMI), a family history of diabetes, and certain ethnic backgrounds [6]. More recently, low thyroid hormone levels during gestation have been postulated as an additional risk factor for GDM [7, 8].

The thyroid hormones play a vital role in fetal growth and neurological development [9]. To produce adequate quantities of these hormones, the body requires a sufficient iodine intake, which, according to the World Health Organization (WHO), corresponds to a minimum daily consumption of $250 \mu \mathrm{g}$ of iodine for pregnant and lactating women [10]. Iodine deficiencies in adults, assessed using urinary iodine concentrations, have been linked with altered insulin and glucose homeostasis [11], mainly via the thyroid hormones [7]. For example, these hormones can reduce the availability of insulin by lowering the half-life of and increasing the breakdown of insulin [12]. Secondly, the expression of glucose transporter 2 in liver cells is increased, resulting in a higher hepatic glucose efflux [12]. In 2013, a nation-wide study in Belgium revealed that iodine intake in women of childbearing age and those in early pregnancy have an inadequate iodine intake [13], resulting in a mild-tomoderate iodine-deficient population. These findings were corroborated within the ongoing ENVironmental Influence ON early AGEing (ENVIRONAGE) birth cohort [14].

Considering the placental iodine concentration as a proxy of long-term iodine intake [15], to our knowledge, no epidemiological studies to date have investigated the association between gestational diabetes mellitus and placental iodine load. We postulate that placental iodine concentrations are linked with the incidence of GDM. Moreover, evidence is lacking whether placental iodine could play a role in the insulin homeostasis, insulin resistance, and $\beta$-cell activity.

\section{Research design and methods Research design}

Mother-newborn pairs were enrolled in the ENVI RONAGE birth cohort. The Ethics Committee of Hasselt University and East-Limburg Hospital (Genk, Belgium) approved the study protocol, which was carried out following the Declaration of Helsinki. All participating mothers were asked to provide written informed consent at the birth of their newborn in the East-Limburg Hospital. Mothers could be included in the cohort if they were able to fill out questionnaires in Dutch, did not have a planned cesarean, and provided written informed consent. Full details of the study protocol were published previously [16].

Questionnaires were used to collect sociodemographic information such as maternal birthdate, education, smoking status, pre-pregnancy body mass index (BMI), alcohol consumption during pregnancy, newborns' ethnicity, and parity. We coded maternal education as "low" (no diploma or primary school), "middle" (high school), and "high" (college or university degree). Smoking status was classified as "non-smokers," "cessation before pregnancy," and "smoked during pregnancy." Alcoholic beverage consumption was categorized as "none" or as "maximally one glass per day." Ethnicity was coded based on the native country of the neonate's grandparents as either "European" (at least two grandparents were European) or "non-European" (at least three grandparents were of non-European origin). For parity, the newborns were coded as primiparous (first child), secundiparous (second child), or multiparous (third or later child).

Medical records of the hospital were used to retrieve information on maternal weight gain during pregnancy, newborns' sex, gestational age, and medical conditions such as GDM, thyroid problems, pre-eclampsia, and hypertension. GDM was determined between the 24th and 28th week of gestation at the hospital via the "twostep" approach of the American Diabetes Association [17]: a 50-g (non-fasting) glucose challenge test (GCT) followed by a 100-g oral glucose tolerance test (OGTT) if the GCT was positive. In short, mothers who had a glycemic value of more than $140 \mathrm{mg} / \mathrm{dL}$ or $7.8 \mathrm{mmol} / \mathrm{L}$ after $1 \mathrm{~h}$ during the GCT moved on to OGTT. During this test, they drank a solution containing $100 \mathrm{~g}$ of glucose, and the glycemic values were measured when sober (threshold $95 \mathrm{mg} / \mathrm{dL}$ or $5.3 \mathrm{mmol} / \mathrm{L}$ ) and after $1 \mathrm{~h}$ (threshold $180 \mathrm{mg} / \mathrm{dL}$ or $10 \mathrm{mmol} / \mathrm{L}$ ), $2 \mathrm{~h}$ (threshold 155 $\mathrm{mg} / \mathrm{dL}$ or $8.6 \mathrm{mmol} / \mathrm{L}$ ), and $3 \mathrm{~h}$ (threshold $140 \mathrm{mg} / \mathrm{dL}$ or $7.8 \mathrm{mmol} / \mathrm{L}$ ). If at least two measurements were above the thresholds, the mother-to-be was diagnosed with GDM.

Blood sampling, biochemical measurements, and HOMAIR determination

We collected cord blood immediately after delivery in an $8 \mathrm{~mL}$ plastic BD Vacutainer ${ }^{\odot}$ Lithium Heparin tubes (BD, Franklin Lakes, NJ, USA) and maternal blood one day after delivery in plastic BD Vacutainer EDTA tube (BD, Franklin Lakes, NJ, USA). Samples were centrifuged at 
$2500 \mathrm{~g}$ for $15 \mathrm{~min}$, and the obtained plasma was frozen at $-80^{\circ} \mathrm{C}$. The clinical laboratory of the East-Limburg Hospital measured the plasma levels of insulin $(\mathrm{pmol} / \mathrm{L})$ and glucose $(\mathrm{mmol} / \mathrm{L})$ with an electro-chemiluminescence immunoassay using the Modular E170 automatic analyzer (Roche, Basel, Switzerland).

The insulin resistance (IR) and $\beta$-cell activity were assessed via the updated Homeostasis Model Assessment (HOMA) [18]. This technique calculates the $\beta$-cell function and IR from basal glucose and insulin concentrations. Therefore, it is necessary to provide clinically realistic values, which are representative for fasting subjects. Thus, plasma glucose should range between 3.5 and $25.0 \mathrm{mmol} / \mathrm{L}$ and plasma insulin concentrations between 20 and $400 \mathrm{pmol} / \mathrm{L}$ [18].

\section{Placental tissue collection and iodine analysis}

Placentas were frozen at $-20^{\circ} \mathrm{C}$ within 10 min after delivery. They were minimally thawed, and biopsies were taken at three standardized locations, situated at $2 \mathrm{~cm}$ from the umbilical cord. We cut away any membranes and rubbed the tissue against a Grade 54 filter paper (GE Healthcare, Chicago, USA) to remove any excess of blood. The tissue samples were stored in metal-free containers (Sterile propylene tubes; VWR, PA, USA) and were frozen at $-20^{\circ} \mathrm{C}$ until iodine determination. For each placenta, equal amounts of the biopsies were pooled from each of the three sampling locations to obtain $500 \mathrm{mg}$ of tissue that was placed in a $0.5 \%$ tetramethylammonium hydroxide (TMAH) solution and heated to $90^{\circ} \mathrm{C}$ for $3 \mathrm{~h}$ in a DigiPREP block digestion system (SCP SCIENCE, Quebec, Canada). Iodine was measured via ICP-MS on an Elan DRC II (Perkin Elmer, MA, USA) on mass ${ }^{127} \mathrm{I}$, with ${ }^{125} \mathrm{Te}$ as an internal standard. A more detailed description of the method is provided by Neven and colleagues [14].

\section{Statistical methods}

Database management and statistical analysis were performed with the SAS software, version 9.4 (SAS Institute, Cary, NC, USA). Mean \pm standard deviation (SD) is given for continuous variables and the proportion for categorical variables. The normality of the data distributions was tested with the Shapiro-Wilk statistic and quantile-quantile plots. To study the possible confounding structure in our data set, we assessed the distributions of continuous variables (ANOVA) and the proportions of categorical variables $\left(\chi^{2}\right.$-statistics $)$ across tertiles of the placental iodine concentrations.

In the first analysis, we assumed that placental iodine concentrations were causally linked to the likelihood of developing GDM. Therefore, we used a multivariate logistic regression model to evaluate the relationship between placental iodine load and the incidence of
GDM. We accounted for the following a priori chosen variables based on previous findings [19]: maternal education, hypertension, smoking status, pre-pregnancy BMI, maternal age at delivery, gestational weight gain, alcohol use, neonatal parity, gestational age, ethnicity, and sex of the neonate. Correction for these variables was done in all the subsequent analyses as well. The results are presented as odds ratios (ORs) with the 95\% confidence intervals $(95 \% \mathrm{CI})$. To assess the public health significance of the GDM findings, we calculated the population attributable fraction (PAF) [20] for the total population and by contrasting the first versus the third tertile of placental iodine load.

In a second analysis, a generalized linear model was used to investigate the relationship of the maternal and cord plasma concentrations of insulin (collected at one day after delivery and at delivery, respectively) with the placental iodine concentrations in non-GDM mothers. In a sensitivity analysis, we included the GDM mothers $(n=12)$. Because the plasma insulin concentrations needed log-transformation to ensure normality, we presented these results as a percent change for a $5 \mu \mathrm{g} / \mathrm{kg}$ increment in placental iodine.

The HOMA-IR method [18] was used in a third analysis to assess the insulin resistance and $\beta$-cell activity in a healthy subset (i.e., excluding mothers with hypertension and/or GDM). We used a mathematical model of fasting plasma glucose and insulin concentrations to estimate insulin sensitivity.

\section{Role of the funding source}

The funder of the study had no role in the study design, data collection, data analysis, data interpretation, or writing the report. The corresponding author had full access to all the data in the study and had final responsibility for the decision to submit for publication.

\section{Results}

Study populations

In the present study, we randomly selected 500 biobanked placentas from 794 mother-neonate pairs who were enrolled in the ENVIRONAGE birth cohort between March 1, 2013, and April 1, 2017 (Additional file 1: Table S1). We included 471 mother-neonate pairs in our first analysis after 29 exclusions: placental iodine below the limit of quantification $(n=2)$, preterm births (i.e., born before 37 weeks of pregnancy; $n=3$ ), pre-eclamptic pregnancies $(n=8)$, and mothers with hyper- or hypothyroidism $(n=16)$. The second analysis involved insulin, for which we used a subset of only 371 pairs because of missing blood samples $(n=78)$ for either mother or child and glucose or insulin measurements $(n=22)$ due to coagulation or a limited amount of plasma. For the analysis concerning HOMA-IR, we 
excluded out-of-range values for plasma glucose (normal range 3.5 to $25.0 \mathrm{mmol} / \mathrm{L}$ ) and plasma insulin (normal range 20 to $400 \mathrm{pmol} / \mathrm{L}$ ) to obtain a final subset of 190 for mothers and 224 for neonates. Figure 1 provides a schematic overview of the study populations.

Table 1 presents the clinical and sociodemographic characteristics of the total population and the different subsets of mother-neonate pairs. In short, for the whole group, 20 mothers (4.3\%) were diagnosed with GDM. Overall, the mothers aged on average 29.4 years (SD 4.4). The mean pre-pregnancy BMI was $24.6 \mathrm{~kg} / \mathrm{m}^{2}$ (4.8), and most mothers never smoked $(n=303[64.3 \%])$ or consumed any alcohol during gestation $(n=407$ [86.4\%]). The mean weight of the neonates was $3462 \mathrm{~g}$ (424) at birth, and $242(51.4 \%)$ were boys. The majority of the neonates had at least two European grandparents $(n=$ $411[87.3 \%])$. The mean gestational age was 39.9 weeks (1.0). Over half of the neonates were primiparous $(n=$ $249[52.8 \%])$ or secundiparous $(n=159$ [33.8\%]).

\section{Placental iodine concentrations and GDM}

After correction for maternal education, hypertension, smoking status, pre-pregnancy BMI, age at delivery, gestational weight gain, alcohol use, neonatal parity, gestational age, ethnicity, and neonates' sex, we observed in the total population that the likelihood of GDM decreased $(\mathrm{OR}=0.82 ; 95 \% \mathrm{CI} 0.72$ to $0.93 ; p$ value $=0.003)$ with increasing placental iodine concentration. In Fig. 2, we contrasted the lowest tertile (i.e., 12.4 to $24.1 \mu \mathrm{g} / \mathrm{kg}$ ) of placental iodine $(n=158)$ with the middle tertile (i.e., 24.1 to $27.6 \mu \mathrm{g} / \mathrm{kg} ; n=157$ ) and the highest tertile (i.e., 27.6 to $40.5 \mu \mathrm{g} / \mathrm{kg} ; n=156$ ). Compared to the lowest tertile, the odds at GDM were significantly lower in the middle tertile $(\mathrm{OR}=0.039 ; 95 \% \mathrm{CI} 0.004$ to 0.36$)$ and the highest tertile ( $\mathrm{OR}=0.22$; $95 \% \mathrm{CI} 0.067$ to 0.72 ).

A total incidence of $20 \mathrm{GDM}$ cases showed, on the basis of placental iodine tertiles, a PAF of 0.4 for the total mother population, indicating that $40 \%$ of the GDM is linked to lower placental iodine. Contrasting the lowest tertile of placental iodine with the highest tertile showed an estimated PAF of $54.2 \%$ (95\%CI 11.4 to $82.3 \% ; p=0.001$ ) of the GDM that could be prevented if all the mothers of the lowest placental iodine tertile ( $\mathrm{I}<24.1 \mu \mathrm{g} / \mathrm{kg}$ ) would have the placental iodine level as the highest tertile $(\mathrm{I} \geq 27.6 \mu \mathrm{g} / \mathrm{kg})$.

\section{Placental iodine and plasma insulin concentrations}

The plasma insulin concentrations for 371 cord and maternal blood samples were available. Pearson's correlations between the plasma insulin concentrations and the placental iodine levels were calculated and are presented in Fig. 3. In a multivariate analysis, for an increase in $5 \mu \mathrm{g} / \mathrm{kg}$ of placental iodine concentration, the insulin concentration in cord blood significantly decreased with $5.0 \%(95 \%$ CI -9.1 to $-0.7 \% ; p=0.022)$. No significant association was observed between placental iodine and maternal insulin concentrations $(p=0.34)$.

\section{Placental iodine concentrations and HOMA-IR}

The HOMA calculator was used to assess the degree of insulin resistance and $\beta$-cell activity [18]. The HOMA-IR index was log-transformed to normalize the distribution. The cord plasma HOMA-IR index was associated with a borderline significant decrease of $7.1 \%(95 \% \mathrm{CI}-14.1 \%$ to $0.5 \%$; $p=0.067$ ) for a $5 \mu \mathrm{g} / \mathrm{kg}$ increment in placental

\begin{tabular}{|l}
\hline placental iodine measured \\
total population - analysis 1
\end{tabular}


Table 1 Clinical and sociodemographic characteristics of the mother and neonate pairs for the total population and subsets

\begin{tabular}{|c|c|c|c|c|}
\hline Characteristics & $\begin{array}{l}\text { Total population } \\
(n=471)\end{array}$ & $\begin{array}{l}\text { Plasma insulin } \\
\text { concentration }(n=371)\end{array}$ & $\begin{array}{l}\text { Cord plasma } \\
\text { HOMA }(n=224)\end{array}$ & $\begin{array}{l}\text { Maternal plasma } \\
\text { HOMA }(n=190)\end{array}$ \\
\hline \multicolumn{5}{|l|}{ Mother } \\
\hline Age, years & $29.4(4.4)$ & $29.3(4.3)$ & $29.0(4.3)$ & $29.4(4.3)$ \\
\hline Pre-pregnancy BMl, kg/m² & $24.6(4.8)$ & $24.2(4.4)$ & $24.9(4.9)$ & $24.6(4.5)$ \\
\hline Net weight gain, kg & $13.9(5.8)$ & $14.2(5.6)$ & $14.5(5.7)$ & $14.3(5.7)$ \\
\hline \multicolumn{5}{|l|}{ Gestational diabetes mellitus } \\
\hline No & $451(95.7 \%)$ & $371(100 \%)$ & $224(100 \%)$ & $190(100 \%)$ \\
\hline Yes & $20(4.3 \%)$ & $0(0 \%)$ & $0(0 \%)$ & $0(0 \%)$ \\
\hline \multicolumn{5}{|l|}{ Hypertension } \\
\hline No & $443(94.1 \%)$ & $350(94.3 \%)$ & $224(100 \%)$ & $190(100 \%)$ \\
\hline Yes & $28(5.9 \%)$ & $21(5.7 \%)$ & $0(0 \%)$ & $0(0 \%)$ \\
\hline \multicolumn{5}{|l|}{ Self-reported tobacco use } \\
\hline Non-smoker & $303(64.3 \%)$ & $240(64.7 \%)$ & $144(64.3 \%)$ & $130(68.4 \%)$ \\
\hline Cessation before pregnancy & $123(26.1 \%)$ & $94(25.3 \%)$ & $59(26.3 \%)$ & $45(23.7 \%)$ \\
\hline Smoked during pregnancy & $45(9.6 \%)$ & $37(10.0 \%)$ & $21(9.4 \%)$ & $15(7.9 \%)$ \\
\hline \multicolumn{5}{|l|}{ Alcohol consumption } \\
\hline None & $407(86.4 \%)$ & $322(86.8 \%)$ & $192(85.7 \%)$ & $169(89.0 \%)$ \\
\hline$Y_{e s}^{a}$ & $64(13.6 \%)$ & 49 (13.2\%) & $32(14.3 \%)$ & $21(11.0 \%)$ \\
\hline \multicolumn{5}{|l|}{ Maternal education ${ }^{b}$} \\
\hline Low & $61(13.0 \%)$ & $52(14.0 \%)$ & $31(13.8 \%)$ & $30(15.8 \%)$ \\
\hline Middle & $157(33.3 \%)$ & $119(32.1 \%)$ & 77 (34.4\%) & 65 (34.2\%) \\
\hline High & $253(53.7 \%)$ & $200(53.9 \%)$ & $116(51.8 \%)$ & 95 (50.0\%) \\
\hline \multicolumn{5}{|l|}{ Newborn } \\
\hline Gestational age, weeks & $39.9(1.0)$ & $39.9(1.0)$ & $40.0(0.9)$ & $39.9(0.9)$ \\
\hline Birth weight, g & $3462(424)$ & 3455 (423) & $3430(427)$ & 3481 (418) \\
\hline Birth length, $\mathrm{cm}^{c}$ & $50.3(1.9)$ & $50.3(1.9)$ & $50.5(1.9)$ & $50.4(1.9)$ \\
\hline \multicolumn{5}{|l|}{ Sex } \\
\hline Male & $242(51.4 \%)$ & $192(51.8 \%)$ & $117(52.2 \%)$ & $104(54.7 \%)$ \\
\hline \multicolumn{5}{|l|}{ Ethnicity $^{d}$} \\
\hline European & $411(87.3 \%)$ & $323(87.1 \%)$ & $192(85.7 \%)$ & $156(82.1 \%)$ \\
\hline Non-European & $60(12.7 \%)$ & 48 (12.9\%) & $32(14.2 \%)$ & $34(17.9 \%)$ \\
\hline \multicolumn{5}{|l|}{ Parity } \\
\hline 1 & $249(52.8 \%)$ & $205(55.3 \%)$ & $110(49.1 \%)$ & $102(53.7 \%)$ \\
\hline 2 & $159(33.8 \%)$ & $121(32.6 \%)$ & 79 (35.3\%) & $58(30.5 \%)$ \\
\hline$\geq 3$ & $63(13.4 \%)$ & $45(12.1 \%)$ & $35(15.6 \%)$ & $30(15.8 \%)$ \\
\hline \multicolumn{5}{|l|}{ Season at delivery } \\
\hline Winter (Dec 21 to March 20) & $109(23.1 \%)$ & $84(22.6 \%)$ & 49 (21.9\%) & $41(21.6 \%)$ \\
\hline Spring (March 21 to June 20) & $112(23.8 \%)$ & $90(24.3 \%)$ & $55(24.5 \%)$ & $45(23.7 \%)$ \\
\hline Summer (June 21 to Sept 22) & $136(28.9 \%)$ & $106(28.6 \%)$ & $60(26.8 \%)$ & $54(28.4 \%)$ \\
\hline Autumn (Sept 23 to Dec 20) & $114(24.2 \%)$ & $91(24.5 \%)$ & $60(26.8 \%)$ & $50(26.3 \%)$ \\
\hline Placental iodine concentration, $\mathrm{\mu g} / \mathrm{kg}$ & $26.1(4.3)$ & $26.1(4.1)$ & $26.1(4.5)$ & $26.5(4.6)$ \\
\hline Cord plasma insulin, pmol/L & - & $36.2(31.2)$ & - & - \\
\hline Maternal plasma insulin, pmol/L & - & $107.2(188.4)$ & - & - \\
\hline Cord plasma glucose, mmol/L & - & $4.5(1.1)$ & - & - \\
\hline
\end{tabular}


Table 1 Clinical and sociodemographic characteristics of the mother and neonate pairs for the total population and subsets (Continued)

\begin{tabular}{|c|c|c|c|c|}
\hline Characteristics & $\begin{array}{l}\text { Total population } \\
(n=471)\end{array}$ & $\begin{array}{l}\text { Plasma insulin } \\
\text { concentration }(n=371)\end{array}$ & $\begin{array}{l}\text { Cord plasma } \\
\text { HOMA }(n=224)\end{array}$ & $\begin{array}{l}\text { Maternal plasma } \\
\text { HOMA }(n=190)\end{array}$ \\
\hline Maternal plasma glucose, mmol/L & - & $4.6(1.5)$ & - & - \\
\hline HOMA-IR index & - & - & $1.0(0.7)$ & $1.5(1.6)$ \\
\hline$\beta$-cell activity, \% & - & - & $106.6(52.0)$ & $134.8(65.2)$ \\
\hline Urinary iodine concentration, $\mu \mathrm{g} / \mathrm{L}^{\mathrm{e}}$ & $69.8(58.3)$ & & & \\
\hline
\end{tabular}

Data are mean (SD) or $n(\%)$

${ }^{a}$ Mothers who consumed a maximum of two glasses of alcoholic beverages per week

${ }^{\mathrm{b}}$ Maternal education was coded as low (no diploma or primary school), middle (high school), and high (college or university degree)

'Data available for 468, 368, 224, and 189 participants, respectively

${ }^{\mathrm{d}}$ Classification of ethnicity is based on the native country of the neonates' grandparents as either European (at least two grandparents were European) or nonEuropean (at least three grandparents were of non-European origin)

${ }^{\mathrm{e}}$ Concentrations were measured for 98 individuals, and were reported previously [14]

iodine load, while the same increment is associated with a lower $\beta$-cell activity (estimate $=-6.7 \%$; $95 \% \mathrm{CI}-14.4$ to $1.1 \% ; p=0.09$ ). The HOMA-IR index for maternal plasma decreased with $11.3 \%(95 \% \mathrm{CI}-22.8$ to $1.9 \%$; $\mathrm{p}=$ $0.09)$ and the $\beta$-cell activity with $10.9 \%(95 \% \mathrm{CI}-21.8$ to $0.0 \% ; p=0.05$ ) for a $5-\mu \mathrm{g} / \mathrm{kg}$ increase in placental iodine.

\section{Sensitivity analyses}

Exclusion of smokers did not alter the previously reported findings, nor did the addition of women with GDM to the models (data not shown).

\section{Discussion}

Iodine deficiencies have been linked with a multitude of adverse health outcomes such as lower IQ points in children [21], attention deficit and hyperactivity disorders [22], and hypothyroidism [10]. The current study adds some key findings to this list: (1) a lower placental iodine load was linked with a higher risk at GDM, and, assuming for causality, over half of the GDM incidence could have been prevented if placental iodine levels of women from the lowest tertile would have been that of the highest tertile; (2) in neonates, the insulin concentration in cord plasma was inversely associated with placental iodine load; and 3) in both maternal and cord plasma, the HOMA-IR index and $\beta$-cell activity were negatively associated with placental iodine load, albeit with a borderline statistical significance.

In the literature on the risk at GDM, the relative importance of iodine sufficiency is still debated. A recent longitudinal case-control study investigated the association of $\mathrm{FT}_{3}, \mathrm{FT}_{4}$, and the $\mathrm{FT}_{3} / \mathrm{FT}_{4}$ ratio with GDM. The authors observed that $\mathrm{FT}_{4}$ concentrations were significantly lower in GDM cases in the first and second trimesters compared to non-GDM controls. At the same time, $\mathrm{FT}_{3}$ and the $\mathrm{FT}_{3} / \mathrm{FT}_{4}$ ratio was higher in women with GDM. Another prospective cohort of 27,513 pregnant women showed that lower levels of free thyroxine in early pregnancy (i.e., 9 to 14 weeks) were a risk factor for GDM incidence, as assessed at weeks 24 to 28 of gestation [7].

In contrast, a Finnish birth cohort found that lower maternal plasma iodine levels in the first trimester of pregnancy were not associated with risk at GDM [23]. However, it should be noted that Bell and colleagues [23] measured iodine in blood plasma, which reflects only the circulating levels of iodine and would, therefore, be a better proxy of thyroid function than iodine status $[24,25]$. Their findings are in contrast to the placental iodine load, which mainly reflects the long-term gestational iodine status of women and hence would be more representative for the iodine status among pregnant women [14, 15]. Assuming for causality, our findings provide evidence of a higher incidence of GDM when placental iodine concentrations were in the lower range $(\mathrm{PAF}=0.4)$. This is in agreement with observations made by Charoenratana et al. [26], as they observed that women in Thailand who were deficient in iodine (measured in urine) during pregnancy had a higher prevalence of GDM compared to iodine-replete women. Interestingly, the Belgian population [13] aligns more with the latter study in terms of gestational iodine deficiency, compared to the Finnish people, whom have lower rates of gestational iodine deficiencies [27]. Although the current evidence seems inconclusive, our findings highlight a possible link between GDM and long-term gestational iodine deficiency.

It is thus plausible that a functional link exists between the iodine status and the onset of diabetes. This link could be traced back to insulin, as it recently became apparent that iodine deficiencies and insulin resistance are tightly related [28]. Several studies pointed out that urinary iodine concentrations were lower in people diagnosed with T2DM compared to the control groups and that the urinary iodine concentrations were inversely linked with the plasma insulin levels and the HOMA-IR index [11, 28, 29]. Although these studies concerning T2DM, GDM and T2DM share a similar 


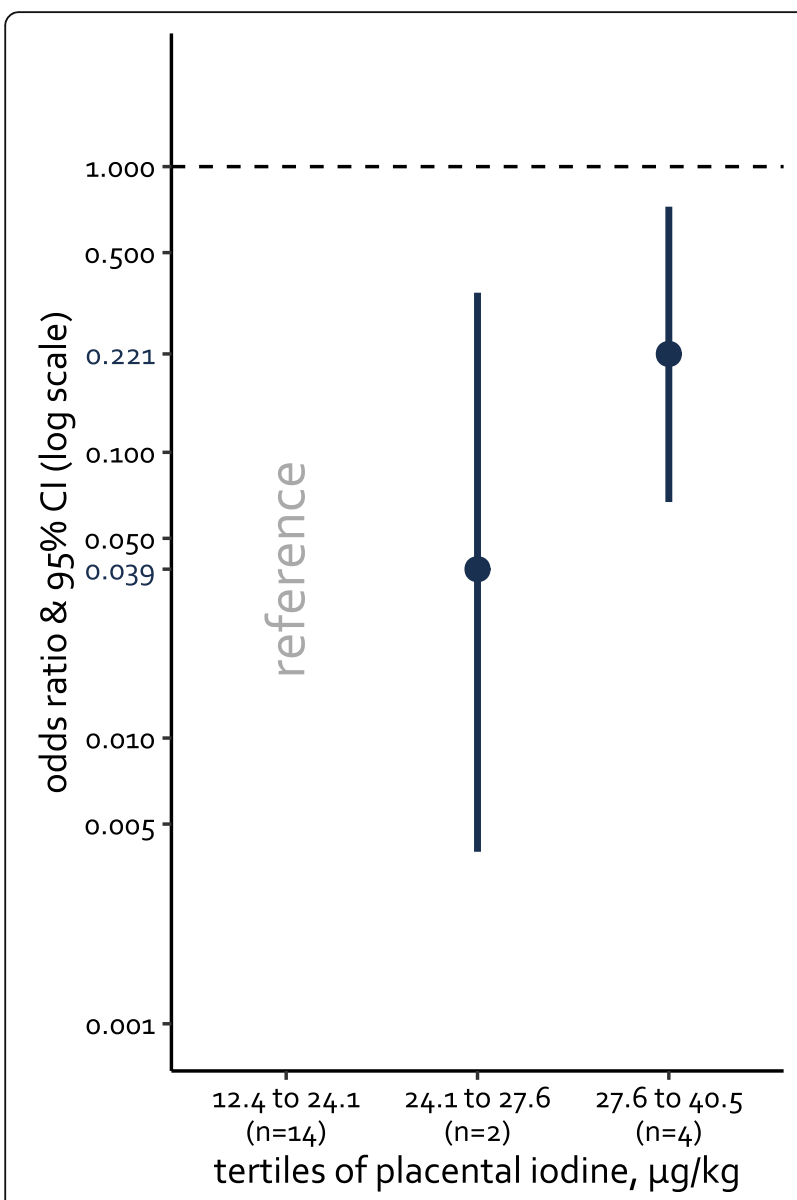

Fig. 2 The placental iodine concentrations ranged from 12.4 to $24.1 \mu \mathrm{g} / \mathrm{kg}$ for the lowest tertile $(n=158), 24.1$ to $27.6 \mu \mathrm{g} / \mathrm{kg}$ for the middle tertile $(n=157)$, and 27.6 to $40.5 \mu \mathrm{g} / \mathrm{kg}$ for the highest tertile $(n=156) . n$ presents the number of women diagnosed with GDM in each tertile. Most mothers with GDM belonged to the lowest tertile $(n=14)$. Only two and four mothers with GDM were in the middle and highest tertiles, respectively. The odds ratio with 95\%

confidence intervals $(95 \% \mathrm{Cl})$ is presented on a log scale. Estimates and $95 \% \mathrm{Cl}$ for the middle and highest tertiles were calculated by contrasting them with the lowest tertile. Corrections were made for maternal education, hypertension, smoking status, pre-pregnancy $\mathrm{BMI}$, maternal age at delivery, gestational weight gain, alcohol use, neonatal parity, gestational age, ethnicity, and sex of the neonate. On the $y$-axis, in red, the estimates are given

pathophysiology: insulin resistance accompanied by a pancreatic $\beta$-cell insufficiency [30]. Along similar lines, we showed that placental iodine inversely associated with the insulin concentrations, the HOMA-IR index, and the $\beta$-cell activity at birth. We could still postulate that a mild-to-moderate iodine deficiency is linked with subclinical and early-onset changes in the insulin homeostasis in healthy pregnant women. Recently, it has been suggested that inflammatory cytokines, secreted by adipose tissue of insulin-resistant patients, and hyperinsulinemia itself could negatively modulate the expression of the sodium/iodide symporter on the apical surface of enterocytes, thus inducing a decrease in iodine absorption $[28,31]$. This implies a functional association (possibly a negative feedback loop) between insulin resistance and iodine deficiency.

Although the exact mechanism is still unclear, it could be postulated that iodine deficiencies lead to an altered thyroid hormone homeostasis and a dysregulation of glucose metabolism [7]. In rodent studies, Kemp and colleagues [12] observed that the glucose transporter 2 expression in the rats' liver, which plays a significant role in maintaining average blood glucose concentrations, was influenced by the thyroid status. Hence, it is possible that an altered thyroid status contributes to an altered hepatic glucose turnover [12]. Another postulated mechanism is that during hyperthyroidism, the half-life of insulin is reduced, the degradation of insulin is heightened, and biologically inactive proinsulin is released [32]. Contrastingly, during hypothyroidism, liver glucose production is decreased [32], which is in line with Kemp et al. [12]. This would lead to lower insulin requirements in diabetic, hypothyroid patients. Another potential mechanism could be investigated via the triage theory of Bruce Ames [33]. According to this theory, episodic shortages in micronutrients are handled in a triage-like allocation mechanism, which prefers short-term "survival" over long-term adverse health effects. Because iodine is involved in various pathways, it is possible that the allocation mechanism could prefer the use of iodine in only a select number of structurally important pathways. For example, the use of iodine in the thyroid hormone production could be a preferred pathway over the use of iodine as an antioxidant agent. Iodine deficiencies have been linked to increased amounts of oxidative stress and a lower antioxidant capacity in pregnant women [34]. Interestingly, women with GDM had a higher presence of oxidative stress in the placenta compared to healthy controls [35]. It could prove informative to investigate a broader range of iodine-associated pathways at the same time in order to examine the effect of mild-to-moderate iodine deficiency thoroughly.

\section{Strengths and limitations}

Our study has several strengths: Firstly, compared to other studies that used urinary iodine concentrations to estimate gestational iodine status, we used the placental iodine load as a marker for long-term gestational iodine accumulation. This biomarker proves to be more reliable and accurate compared to the short-term feature of urinary iodine concentrations [14, 15]. Secondly, the diagnosis of GDM was assessed by using the clinical biomarkers (i.e. GCT and OGTT) and performed by physicians from the recruitment hospital according to the American Diabetes Association guidelines [17]. Thirdly, 

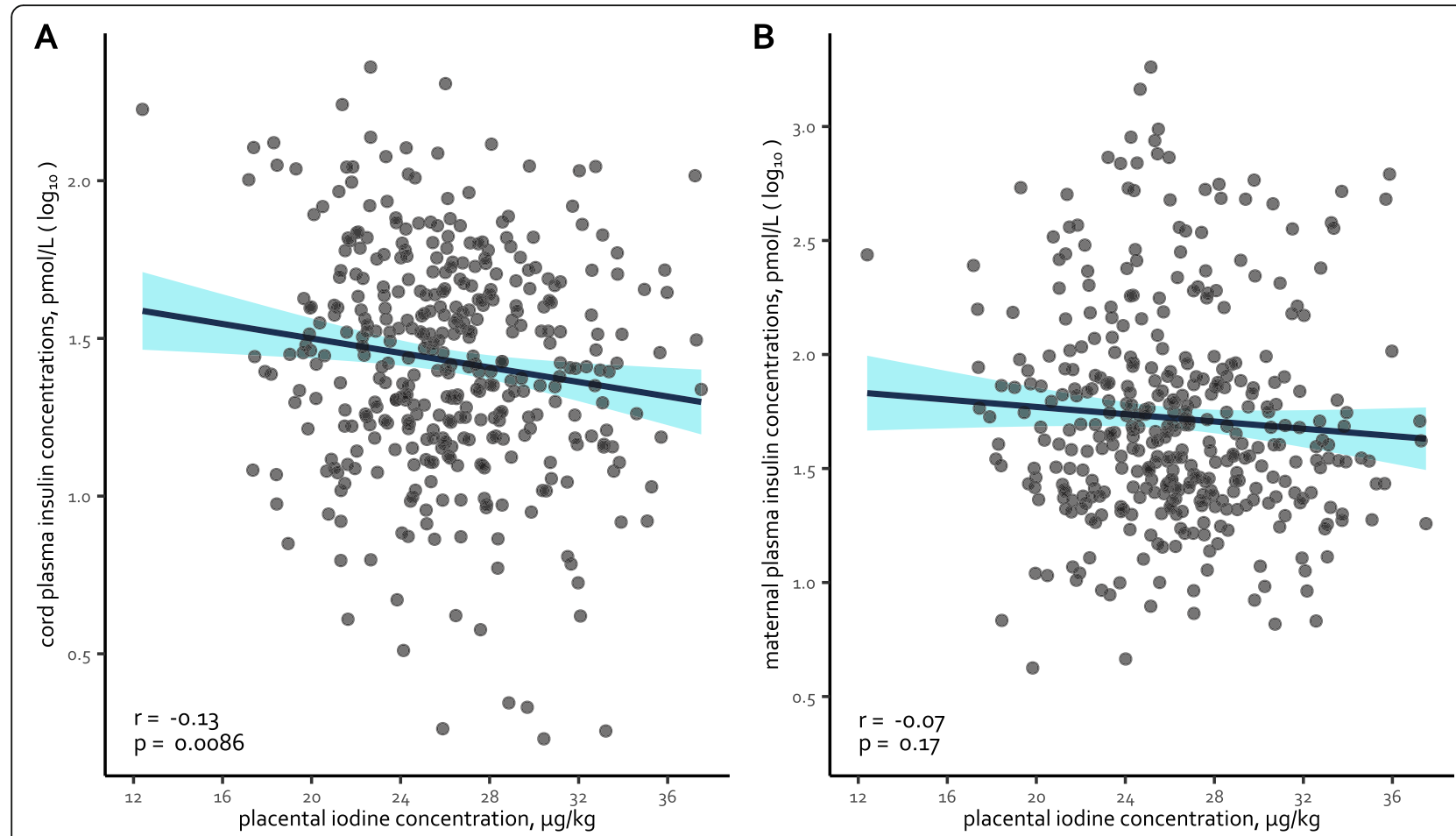

Fig. 3 Correlation between cord (a) and maternal (b) plasma insulin and the placental iodine concentration $(n=371)$. Cord blood was collected at delivery, while maternal blood was sampled one day after delivery. Pearson's correlation $(r)$ was calculated and the corresponding $p$ value is presented

our findings are generalizable to the Belgian gestational population (Additional file 2: Table S2).

We acknowledge some potential limitations. Because we used placental iodine concentrations of term-born children, no dynamic time-dependent iodine concentrations could be determined. The number of women diagnosed with GDM in the current study is low $(n=20 ; 4.3 \%)$. Nevertheless, this incidence of GDM is generally found for normal populations [2]. Moreover, our PAF calculation estimated that over $50 \%$ of the GDM cases could be prevented, which is in line with findings from a meta-analysis by Toulis and colleagues [8], who provided evidence that the risk at GDM increased by $50 \%$ in women with subclinical hypothyroidism. Given the observational study design, we cannot infer a causal link between placental iodine load and GDM. Even though previous findings indicated that an altered thyroid hormone status is more likely to cause GDM, it is still possible for GDM to affect thyroid hormones. For example, in diabetic patients, the thyroidstimulating hormone response to the thyrotropinreleasing hormone is impaired [32]. Moreover, the peripheral conversion from thyroxine to triiodothyronine in diabetics could be impaired as well [32].

\section{Conclusions}

Gestational iodine intake is essential as it provides a healthy intrauterine environment for optimal fetal growth. The current study sheds some light on the link between placental iodine load and the heightened risk at GDM, as well as an association with altered plasma insulin concentration, HOMA-IR index, and $\beta$-cell activity. The specific mechanisms of how the iodine status, prior to, and during gestation could heighten the risk at GDM remains to be unraveled. Nevertheless, our findings on GDM and placental iodine may help to improve the understanding of the developmental origins of health and disease. Our study coveys an important public health message, in that maintaining an adequate iodine status in the population at large may avert a significant portion of gestational diabetes mellitus and adverse health effects later in the neonates' life.

Clinicians and healthcare managers should keep in mind that combatting iodine deficiency is complex and needs careful planning, even before pregnancy. Current evidence suggests that starting iodine supplementation during gestation might not be the most effective method to optimize the iodine supply to the mother and fetus [36].

\section{Supplementary Information}

The online version contains supplementary material available at https://doi. org/10.1186/s12916-021-01919-4.

Additional file 1: Table S1. Maternal and neonate characteristics of 1) the original population of 794 mother-neonate pairs who were enrolled 
in the ENVIRONAGE birth cohort between March $1^{\text {st }}, 2013$ and April $1^{\text {st }}$ 2017; 2 ) The randomly selected population $(n=498)$ for which we had placental iodine concentrations; and 3) the final study population ( $n=$ 471) after exclusion of preterm births, pre-eclamptic pregnancies, and mothers with thyroid problems.

Additional file 2: Table S2. Maternal and neonate characteristics of the current study group $(n=471)$ compared with a reference population of births in Flanders, Belgium (born 2002 until 2011; $n=606,877$ ).

\section{Abbreviations}

Cl: Confidence intervals; ENVIRONAGE: Environmental Influences ON Early Ageing; GDM: Gestational diabetes mellitus; OR: Odds ratio; PAF: Population attributable factor; SHS: Second-hand smoke; SD: Standard deviation; T2DM: Type 2 diabetes mellitus; TMAH: Tetramethylammonium hydroxide

\section{Authors' contributions}

TSN is the coordinator of the ENVIRONAGE birth cohort and designed the current study with KYN, AR, and KV. KYN and WG recruited the participants at the hospital. KYN, CC, and JP measured the samples. KYN did the statistical analysis, with guidance provided by TSN and BC. Data interpretation was made by TSN, KV, MP, and KYN. KYN wrote the first draft of the manuscript, with the help of TSN. HAR made critical revisions of the manuscript. All authors critically reviewed and approved the manuscript.

\section{Funding}

The work is supported by the European Research Council (ERC-2012StG.310898 and ERC-2011-StG.282413) and the Flemish Scientific Fund (FWO, G073315N). Bianca Cox and Karen Vrijens are post-doctoral fellows at the FWO (12Q0517N and 12D7718N, respectively).

\section{Availability of data and materials}

The datasets used and/or analyzed during the current study are available from the corresponding author on reasonable request.

\section{Ethics approval and consent to participate}

The study protocol was approved by the ethics committees of Hasselt University and East-Limburg Hospital. Mothers proved us with written informed consent before delivery.

\section{Consent for publication}

Not applicable.

\section{Competing interests}

The authors declare no competing interests.

\section{Author details}

${ }^{1}$ Centre for Environmental Sciences, Hasselt University, Diepenbeek, Belgium. ${ }^{2}$ Department of Obstetrics, East-Limburg Hospital, Genk, Belgium. 'aboratory of Clinical Biology, East-Limburg Hospital, Genk, Belgium. ${ }^{4}$ Louvain Centre for Toxicology and Applied Pharmacology, Université catholique de Louvain, Brussels, Belgium. ${ }^{5}$ Sciensano, SD Chemical and Physical Health Risks, Tervuren, Belgium. ${ }^{6}$ Department of Public Health \& Primary Care, Leuven University, Leuven, Belgium.

Received: 3 August 2020 Accepted: 19 January 2021

Published online: 19 February 2021

\section{References}

1. Jovanovic L, Pettitt DJ. Gestational diabetes mellitus. JAMA. 2001;286(20): 2516-8

2. Ben-Haroush A, Yogev $Y$, Hod M. Epidemiology of gestational diabetes mellitus and its association with type 2 diabetes. Diabet Med. 2004;21(2): 103-13.

3. Buchanan TA, Xiang AH, Page KA. Gestational diabetes mellitus: risks and management during and after pregnancy. Nat Rev Endocrinol. 2012;8(11): 639-49.

4. Bellamy L, Casas JP, Hingorani AD, Williams D. Type 2 diabetes mellitus after gestational diabetes: a systematic review and meta-analysis. Lancet. 2009; 373(9677):1773-9.
5. Simeoni U, Barker DJ. Offspring of diabetic pregnancy: long-term outcomes. Semin Fetal Neonatal Med. 2009:14(2):119-24.

6. The Lancet. Gestational diabetes in England: cause for concern. Lancet. 2019:393(10178):1262.

7. Yang S, Shi FT, Leung PC, Huang HF, Fan J. Low thyroid hormone in early pregnancy is associated with an increased risk of gestational diabetes mellitus. J Clin Endocrinol Metab. 2016;101(11):4237-43.

8. Toulis KA, Stagnaro-Green A, Negro R. Maternal subclinical hypothyroidsm and gestational diabetes mellitus: a meta-analysis. Endocr Pract. 2014;20(7):703-14.

9. Glinoer D. The regulation of thyroid function during normal pregnancy: importance of the iodine nutrition status. Best Pract Res Clin Endocrinol Metab. 2004;18(2):133-52.

10. WHO - UNICEF - ICCIDD: Assessment of iodine deficiency disorders and monitoring their elimination. A guide for programme managers. In., 3rd edn. Switzerland: World Health Organization; 2007.

11. Al-Attas OS, Al-Daghri NM, Alkharfy KM, Alokail MS, Al-Johani NJ, AbdAlrahman SH, Yakout SM, Draz HM, Sabico S. Urinary iodine is associated with insulin resistance in subjects with diabetes mellitus type 2. Exp Clin Endocrinol Diabetes. 2012;120(10):618-22.

12. Kemp HF, Hundal HS, Taylor PM. Glucose transport correlates with GLUT2 abundance in rat liver during altered thyroid status. Mol Cell Endocrinol. 1997;128(1-2):97-102.

13. Vandevijvere $S$, Amsalkhir S, Mourri AB, Van Oyen H, Moreno-Reyes R. lodine deficiency among Belgian pregnant women not fully corrected by iodinecontaining multivitamins: a national cross-sectional survey. Br J Nutr. 2013; 109(12):2276-84

14. Neven KY, Marien CBD, Janssen BG, Roels HA, Waegeneers N, Nawrot TS, Ruttens A: Variability of iodine concentrations in the human placenta. Sci Rep 2020, 10(1):161.

15. Burns R, Azizi F, Hedayati M, Mirmiran P, O'Herlihy C, Smyth PP. Is placental iodine content related to dietary iodine intake? Clin Endocrinol. 2011;75(2): $261-4$

16. Janssen BG, Madhloum N, Gyselaers W, Bijnens E, Clemente DB, Cox B, Hogervorst J, Luyten L, Martens DS, Peusens M, et al. Cohort Profile: The ENVIRonmental influence ON early AGEing (ENVIRONAGE): a birth cohort study. Int J Epidemiol. 2017;46(5):1386-1387m.

17. American Diabetes Association: 2. Classification and Diagnosis of Diabetes: Standards of Medical Care in Diabetes-2018. Diabetes Care 2018, 41(Suppl 1):S13-S27.

18. Levy JC, Matthews DR, Hermans MP. Correct homeostasis model assessment (HOMA) evaluation uses the computer program. Diabetes Care. 1998;21(12): 2191-2.

19. Neven KY, Cox B, Vrijens K, Plusquin M, Roels HA, Ruttens A, Nawrot TS. Determinants of placental iodine concentrations in a mild-to-moderate iodine-deficient population: an ENVIRONAGE cohort study. J Transl Med. 2020;18(1):426.

20. Rowe AK, Powell KE, Flanders WD. Why population attributable fractions can sum to more than one. Am J Prev Med. 2004;26(3):243-9.

21. Bath SC, Steer CD, Golding J, Emmett P, Rayman MP. Effect of inadequate iodine status in UK pregnant women on cognitive outcomes in their children: results from the Avon Longitudinal Study of Parents and Children (ALSPAC). Lancet. 2013;382(9889):331-7

22. Vermiglio F, Lo Presti VP, Moleti M, Sidoti M, Tortorella G, Scaffidi G, Castagna MG, Mattina F, Violi MA, Crisa A, et al. Attention deficit and hyperactivity disorders in the offspring of mothers exposed to mildmoderate iodine deficiency: a possible novel iodine deficiency disorder in developed countries. J Clin Endocrinol Metab. 2004;89(12):6054-60.

23. Bell GA, Mannisto T, Liu A, Kannan K, Yeung EH, Kim UJ, Suvanto E, Surcel HM, Gissler M, Mills JL. The joint role of thyroid function and iodine concentration on gestational diabetes risk in a population-based study. Acta Obstet Gynecol Scand. 2019;98(4):500-6.

24. Soldin OP. Controversies in urinary iodine determinations. Clin Biochem. 2002:35(8):575-9.

25. Liberman CS, Pino SC, Fang SL, Braverman LE, Emerson CH. Circulating iodide concentrations during and after pregnancy. J Clin Endocrinol Metab. 1998:83(10):3545-9.

26. Charoenratana $C$, Leelapat $P$, Traisrisilp $K$, Tongsong T. Maternal iodine insufficiency and adverse pregnancy outcomes. Matern Child Nutr. 2016; 12(4):680-7. 
27. Nystrom HF, Brantsaeter AL, Erlund I, Gunnarsdottir I, Hulthen L, Laurberg P, Mattisson I, Rasmussen LB, Virtanen S, Meltzer HM. Iodine status in the Nordic countries - past and present. Food Nutr Res. 2016;60:31969.

28. Malaguarnera R, Vella V, Nicolosi ML, Belfiore A. Insulin resistance: any role in the changing epidemiology of thyroid cancer? Front Endocrinol (Lausanne). 2017:8:314.

29. Mansourian AR. A review on the metabolic disorders of iodine deficiency. Pak J Biol Sci. 2011;14(7):412-24.

30. Robitaille J, Grant AM. The genetics of gestational diabetes mellitus: evidence for relationship with type 2 diabetes mellitus. Genet Med. 2008; 10(4):240-50

31. Lecube A, Zafon C, Gromaz A, Fort JM, Caubet E, Baena JA, Tortosa F. lodine deficiency is higher in morbid obesity in comparison with late after bariatric surgery and non-obese women. Obes Surg. 2015;25(1):85-9.

32. Hage M, Zantout MS, Azar ST. Thyroid disorders and diabetes mellitus. J Thyroid Res. 2011;2011:439463.

33. Ames BN. Low micronutrient intake may accelerate the degenerative diseases of aging through allocation of scarce micronutrients by triage. Proc Natl Acad Sci U S A. 2006;103(47):17589-94.

34. Vidal ZE, Rufino SC, Tlaxcalteco EH, Trejo CH, Campos RM, Meza MN, Rodriguez RC, Arroyo-Helguera O. Oxidative stress increased in pregnant women with iodine deficiency. Biol Trace Elem Res. 2014;157(3):211-7.

35. Coughlan MT, Vervaart PP, Permezel M, Georgiou HM, Rice GE. Altered placental oxidative stress status in gestational diabetes mellitus. Placenta. 2004;25(1):78-84.

36. Dineva M, Fishpool H, Rayman MP, Mendis J, Bath SC. Systematic review and meta-analysis of the effects of iodine supplementation on thyroid function and child neurodevelopment in mildly-to-moderately iodinedeficient pregnant women. Am J Clin Nutr. 2020;112(2):389-412.

\section{Publisher's Note}

Springer Nature remains neutral with regard to jurisdictional claims in published maps and institutional affiliations.

Ready to submit your research? Choose BMC and benefit from:

- fast, convenient online submission

- thorough peer review by experienced researchers in your field

- rapid publication on acceptance

- support for research data, including large and complex data types

- gold Open Access which fosters wider collaboration and increased citations

- maximum visibility for your research: over $100 \mathrm{M}$ website views per year

At $\mathrm{BMC}$, research is always in progress.

Learn more biomedcentral.com/submissions 